\title{
KISAH DHRUVA SEBAGAI MEDIA PENDIDIKAN KARAKTER PADA ANAK
}

\author{
Oleh: \\ Ni Kadek Dwi Lestari \\ Mahasiswa Jurusan PGSDH Fakultas Dharma Acarya \\ Institut Hindu Dharma Negeri Denpasar \\ dwiklestari1996@gmail.com
}

diterima 6 Februari 2019, direvisi 8 Februari 2019, diterbitkan 29 April 2019

\begin{abstract}
This paper aims to describe the personality prominent of characteristics from Visnu Puraana of Dhruva story. the author describes many phenomena that indicate the decline of the morality of generations such as: elementary school children who have been smoking, teenagers who are exposed to free sex, lack of tolerance in social life, and there is a shift in values regarding norms of decency and ethics. Weak understanding of religious values can be regarded as an indicator of moral degradation. A civilization would want more improvement in regards to morality. In relation to the moral degradation of the nation's generation the government and society want children to have 18 national characteristics being; believe in religion, honesty, tolerance, fair for all, discipline, hardworking, creative, independent, democratic, curios to learn, national pride, communicative, peace-loving, avid readers, caring about the environment, social care, and responsibility. Building character using education for children is one way to make civilization better. The cultivation of character using education for children starts from an early age, ie through story or stories in Puraana that can be used as a medium of character building for children.
\end{abstract}

Key Word: Story of Dhruva, Medium, Character Education

\section{PENDAHULUAN}

Perubahan pasti terjadi, namun dalam dalam setiap peradaban tentu menginginkan sebuah perubahan yang lebih baik. Seperti halnya dalam pendidikan, yang mengharapkan output yang berkarakter sesuai dengan 18 nilai pendidikan karakter bangsa (dalam http://rumahinspirasi.com/18-nilaidalam-pendidikan-karakter-bangsa/) yaitu religius, mandiri, disiplin, kerja keras, demokratis, rasa ingin tahu, kreatif, cinta tanah air, semangat kebangsaan, jujur, peduli sosial, peduli lingkungn, cinta damai, komunikatif, toleransi, menghargai prestasi, gemar membaca dan tanggung jawab. Menurut Yupardhi (2012) bahwa refleksi karakter manusia yang baik memiliki ciri ciri : 1) tindakannya konstruktif, 2) percaya diri, 3) mempunyai rasa memiliki (sense of belonging) 4). memiliki rasa cinta terhadap pekerjaannya, 5) mempunyai pandangan luas ke depan, 6) mampu menyelesaikan persoalan, 7) dapat menyesuaikan diri dan berkontribusi positif terhadap lingkungannya, 8). mempunyai kekuatan untuk mewujudkan potensinya, 9) mulia, 10) jujur, 11) berbudi luhur, 12) cerdas, 13) rendah hati, 14) saling 
menghormati satu sama lain, 15) tidak menjelek-jelekan orang lain, 16) selalu berada di jalan Tuhan 17) tidak korupsi, 18). tidak memfitnah, 19) tidak mementingkan diri sendiri, 20) bertanggungjawab secara horizontal maupun vertikal, 21) inovatif dan kreatif, 22) profesional, 23) efisien, 24) Menggunakan logika, 25) selalu memperbaikiidiri, 26) berprestasi.

Kenyataan yang terjadi saat ini menyangkut karakter bangsa sangatlah memprihatinkan, walaupun belum semua remaja atau generasi muda memiliki moral yang rendah namun dikhawatirkan suatu saat nanti akan ada lebih banyak generasi muda yang memiliki penurunan moral, seperti yang telah terjadi pada masa kini, yang telah mengundang keprihatinan dari berbagai pihak. Hal ini dipertegas oleh Lickona, 2013 (dalam Wiguna, 2018) bahwa ada 10 indikator bobroknya moral di kalangan remaja yakni: 1) Meningkatnya tindak kekerasan dan vandalisme, 2) Pencurian, 3) Budaya ketidakjujuran, 4) Menurunnya rasa hormat terhadap orangtua, guru atau figur otoritas, 5) Kekejaman terhadap teman sebaya, 6) Kefanatikan yang menghilangkan sikap toleransi, 7) Penggunaan bahasa yang kasar, 8) Pelecehan seksual, 9) Meningkatnya sifat mementingkan diri sendiri dan menurunnya tanggung jawab serta etos kerja, dan 10) Prilaku merusak diri seperti penggunaan obat-obatan terlarang, seks bebas, minuman keras dan sebagainya.

Kemorosotan moral tersebut merupakan ciri dari lemahnya pemahaman manusia mengenai ajaran agama. Agama yang seyoginya dapat menuntun umat manusia ke arah yang lebih baik hanya dijadikan sebagai simbol dalam bermasyarakat tanpa diketahui maknanya. Dalam mempelajari agama, tidaklah sulit karena kini ajaran ajaran agama sudah tertuang dalam bentuk cerita yang disusun dalam Itihasa dan Puraana. Dalam Wiguna,(2018) Ajaran Agama Hindu bersumber dari Catur Veda, dan dijabarkan ke dalam kitab-kitab Smrti serta susastra-susastra Hindu. Kemahiran para Maharsi, Mahaguru, yang mampu menghimpun dan meramu pengetahuannya dalam menyusun susastra-susastra, menjadikannya sebagai sumber acuan nilai religius maupun didaktif atau pendidikan, serta menjadi pedoman dalam berprilaku yang baik melalui ajaran moralitas dan etika yang dikemas dalam alur cerita dan penggunaan gaya bahasanya yang indah.

Keberadaan kesusastraan Hindu sangat berperan bagi umat manusia, seperti cerita - cerita yang terkandung dalam Ramayana dan Mahabharata yang sudah banyak diketahui masyarakat. Selain Itihasa terdapat kesusastraan Hindu lainnya yakni Puraana. Dalam Puraana juga menceritakan kisah $\quad-$ kisah perjalalan seorang raja, kerajaan besar, dan masih banyak lagi sama halnya dalam Itihasa yang memiliki banyak pendidikan karakterk di dalamnya. Pemahaman agama dapat memberikan kesadaran serta menuntun umat manusia dalam berpikir, berkata, maupun berbuat dalam kebenaran. Sebagaimana harapan bangsa yakni membentuk anak memiliki 18 karakter kebangsaan. Membangun pendidikan karakter pada anak merupakan salah satu cara menjadikan peradaban menjadi lebih baik. Penanaman pendidikan karakter pada anak di mulai dari sejak dini, yakni melalui 
cerita - cerita atau kisah - kisah dalam Puraana yang dapat digunakan sebagai media penanaman pendidikan karakter pada anak.

Media berasal dari bahasa latin " medius" yang secara harfiah berarti prantara atau pengantar. Oleh karena itu, media dapat diartikan sebagai suatu perantara atau pengantar pesan dari pengirim ke penerima pesan (Arsyad, 2002; Sadiman, dkk., 1990 dalam http://gusdanela.blogspot.com/2014/ 02/pengertian-media-menurutbeberapa ahli.html)

Menurut Lickona (dalam http://belajarpsikologi.com/pengertia n-pendidikan-karakter/) pendidikan karakter adalah suatu usaha untuk membimbing seseorang mampu memahami serta melakukan pengamalan nilai - nilai karakter bangsa. Dengan demikian media pendidikan karakter merupakan suatu perantara yang dapat digunakan dalam menciptakan suatu pemahaman pada anak sehingga anakmemiliki nilai karakter yang diharapkan.

\section{METODE}

Dalam jurnal ini, penulis menggunakan jenis penelitian kepustakaan (library research), yaitu penelitian yang dilakukan dengan cara membaca berbagai literature yang berkaitan dengan penelitian, kemudian mencatatatnya untuk membentuk suatu pemahaman baru. Menurut Abdul Rahman Sholeh (2005:63) penelitian kepustakaan (library research) ialah penelitian yang mengunakan cara untuk mendapatkan data informasi dengan menempatkan fasilitas yang ada di perpus, seperti buku, majalah, dokumen, catatan kisah-kisah sejarah atau penelitian kepustakaan murni yang terkait dengan obyek penelitian.

Tulisan dalam jurnal ini menggunakan studi kepustakaan dengan sumber data sekunder yakni data yang diperoleh melalui data data yang sudah ada atau tidak langsung diperoleh dari subyek penelitian. Dalam studi ini data sekundernya adalah buku - buku yang relevan dengan judul penulis. Dalam hal ini, sumber data sekunder berupa tulisan yang membahas tentang kisah - kisah dalam Itihasa maupun Puraana.

\section{HASIL DAN PEMBAHASAN}

Kesusastraan Hindu dapat berperan dalam hal pendidikan karakter. Jika disadari banyak nilai yang terkandung di dalamnya, tidak hanya menyangkut ajaran agama namun juga menandung nilai - nilai pendidikan seperti nilai etika dan moralitas. Alur cerita dan penggunaan gaya bahasa yang indah menjadikan kesusastraan mudah diterima masyarakat baik anak anak maupun orang dewasa. Membentuk anak yang berkarakter memang tidak mudah, namun bukan berarti hal itu mustahil dilakukan (Wiguna, 2018). Ada berbagai upaya yang dapat dilakukan untuk membangun generasi yang berkarakter, salah satu cara adalah melalui penanaman pendidikan karakter yang terkandung dalam kesusastraan hindu pada anak. Menurut Kertajaya (dalam http://belajarpsikologi.com/pengertia n-pendidikan-karakter/) Karakter merupakan suatu ciri yang dimiliki oleh suatu benda atau individu yang dimiliki sejak mereka diciptakan serta telah mengakar pada kepribadian benda atau individu tersebut seperti "mesin" yang 
mendorong bagaimana seorang bersikap, berucap, dan bertindak melakukan sesuatu.

Berbicara mengenai karaker yang baik tidak terlepas dari proses pembentukannya yang sering dikaitkan dengan pendidikan budhi pekerti. Ada beberapa indikator keberhasilan pendidikan budhi pekerti dengan kata lain terbentuknya generasi yang berkarakter menurut Titib, 2003: 127-128 (dalam Wiguna, 2018) antara lain : 1) Rajin dan taat sembahyang terutama Tri Sandhya, 2) Senantiasa berdoa, sebelum menikmati makanan, bepergian, dan selalu ingat kepada-Nya, 3) Rajin membersihkan rumah dan lingkungannya, 4) Rajin belajar, 5) Hormat dan sopan kepada orangtua, saudara-saudara, dan dengan tamu yang datang ke rumah, 6) Jujur dalam mengungkapkan masalah yang dihadapi, 7) Terampil dalam pekerjaan, 8) Tidak mengeluh ketika menghadapi suatu permasalahan yang berat, 9) Terlatih melayani dan mengutamakan kepentingan orang lain daripada kepentingannya sendiri.

Dalam Puraana berisikan berbagai kisah yang merupakan bentuk terjemahan dari beberapa penekun kesusastraan dengan isi cerita yang diulas lebih ringkas. Namun hal itu bukan sebagai hambatan dalam menggali nilai nilai yang terkandung didalamnya, melalui karakter yang ditonjolkan oleh tokoh - tokoh di dalam kisah tersebut (Wiguna, 2018). Dalam cerita ini diharapkan dapat menambah wawasan serta pemahaman tentang ajaran Agama Hindu terkait pendidikan karakter.

\section{Kisah Dhruva}

Kisah Dhruva diambil dari kesusastraan Visnu Puraana mengisahkan tentang anak dari seorang raja bernama Uttanapada yang memiliki dua orang istri bernama Suruchi dan Suniti. Suruchi melahirkan seorang anak bernama Uttama, dan Suniti melahirkan anak bernama Dhruva. Raja Uttanapada tidak adil akan pembagian kasih sayang yang ia berikan kepada kedua istri dan anaknya. Raja Uttanapada lebih mencintai dan menyayangi Suruchi dan Uttama daripada Suniti dan dhruva. Hingga pada suatu hari dhruva melihat Uttama berada di pangkuan ayahnya, dalam naluri seorang anak, Dhruva juga menginginkan hal yang sama dengan seketika ia berlari kearah ayahnya namun dihalangi oleh Suruchi. Suruchi memarahi dhruva dengan berkata bahwa ia tidak boleh memiliki apa yang dimiliki oleh Uttama. Ia harus selalu ingat bahwa tahta itu hanya dimiliki oleh Uttama bukan Dhruva.

Mendengar hal itu, Dhruva merasa sedih kemudian ia berlari kepada ibunya. Dhruva memberitahu ibunya tentang apa yang telah terjadi, namun Suniti menghibur Dhruva dengan berkata bahwa manusia menderita atau bahagia itu bergantung pada perbuatan masa lampaunya. Jika orang yang melakukan kebaikan pada masa lampaunya maka dikehidupan sekarang ia bisa menjadi seorang raja dengan payung kebesaran menutupi tahtanya ((Bibek Debroy, 2000, Visnu Puraana, 9-10) . Mungkin Suruchi dan Uttama dulu selalu berbuat kebaikan di masa lampau kehidupannya, dan mungkin aku dan kau anakku, kita telah melakukan perbuatan yang tidak baik. Namun 
apapun yang kau dapatkan saat ini janganlah kau sesali, karena orang bijak akan selalu puas dengan apa yang telah ia miliki. Jika kau benar benar kecewa atas apa yang dilakukan oleh Suruchi, maka seharusnya kau tidak boleh bersedih hati dan sebaliknya, kau harus menghabiskan waktumu untuk berbuat baik dan berbuat tanpa pamrih.

Mendengar perkataan ibunya, Dhruva merasa tenang dan berkata terima kasih bu, perkataanmu sungguh menyejukkan hati. Kau benar, tak sepantasnya aku merasa sedih atas semua yang terjadi padaku. Aku akan berusaha untuk mendapatkan posisi tertinggi dengan usahaku sendiri. Memang benar sang raja menyayangi Suruchi dan Uttama. Aku bukan putranya. Tapi aku adalah putramu, aku akan menunjukkan padamu apa yang bisa aku lakukan. Biarkan Uttama yang mendapatkan tahta, karena aku tidak mau memiliki sesuatu yang menjadi milik orang lain. Dengan usahaku sendiri, aku akan mendapatkan apa yang belum pernah didapatkan oleh ayahku sendiri (Bibek Debroy, 2000, Visnu Puraana, 10) .

Setelah mengatakan hal itu, Dhruva kemudian pergi ke hutan, di sana ia menemui tujuh maha Rsi (Sapta Rsi). Dhruva kemudian bersujud dan menceritakan kisahnya pada ketujuh maha Rsi tentang apa yang telah dialaminya. Ia berkata bahwa ia tidak menginginkan harta maupun kerajaan. Ia mengatakan kepada maha rsi bahwa ia hanya menginginkan untuk bisa pergi ke tempat yang tak seorangpun pernah mendatanginya. Mendengar hal tersebut, para rsi menyarankan Dhruva untuk berdoa kepada Visnu.
Kemudian para rsi mengajarkan Dhruva mantra yang digunakan untuk berdoa pada Visnu.

Kemudian Dhruva berjalan menuju pinggir sungai Yamuna dan di sanalah Dhruva berdoa. Ia berdoa begitu tulus, sehingga para dewa mulai khawatir jikalau Dhruva menginginkan hal yang tidak baik, takut jika Dhruva ingin menjadi Indra, Kubera atau Surya. Sehingga berbagai upaya telah dilakukan para dewa untuk menggagalkan pertapaan Dhruva. Namun karena keteguhan dan ketulusan hati Dhruva, rencana para dewa untuk menggagalkan pertapaannya gagal hinga akhirnya deva Visnu menampakan wujudnya di hadapan Dhruva. Visnu bertanya anugrah apa yang diinginkan Dhruva, namun Dhruva mengatakan tidak menginginkan anugerah apapun. Ia sudah sangat merasa puas dapat melihat Visnu dan menjadi pemuja Visnu yang setia.

Dewa Visnu tetap menginginkan Dhruva meminta anugerah padaNya. Hingga akhirnya Dhruva meminta anugerah agar ia bisa tinggal di puncak alam semesta, kemudian Visnu memberkati keinginannya. Beliau juga memberitahukan bahwa dalam kehidupan yang sebelumnya, ia adalah seorang braahmana yang memuja Visnu dengan setia. Braahmana ini mempunyai teman seorang pangeran yang kaya raya dan tampan. Setelah mendapatkan anugrah Visnu, braahmana itu kemudian menginginkan agar ia lahir sebagai seorang pangeran dalam kehidupan selanjutnya. Oleh karena itulah kemudian ia lahir menjadi Dhruva putra dari raja Uttanapada. Tapi karena Dhruva tidak lagi menginginkan kerajaan atau 
kekayaan, Visnu kemudian menempatkannya di tengah langit sehingga seluruh bintang berputar mengelilinginya. Ibunya, Suniti, juga ditempatkan di langit, didekatnya. (Maswinara,2001).

\section{Kisah Dhruva Sebagai Media Pendidikan karakter Pada Anak}

Dari kutipan cerita di atas, dapat dilihat pendidikan karakter yang terkandung di dalamnya yang dapat dijadikan sebagai media pendidikan karakter pada anak. Media merupakan sebuah medium yang digunakan sebagai perantara dalam penyapaian pesan kepada penerima pesan. Menurut Arsyad \& Sadiman, dkk menyatakan bahwa Media berasal dari bahasa latin " medius" yang secara harfiah berarti prantara atau pengantar. Oleh karena itu, media dapat diartikan sebagai suatu perantara atau pengantar pesan dari pengirim ke penerima pesan. Sedangkan Menurut Gerlach \& Ely (dalam Arsyad, 2002), seluruh benda maupun orang yang ada di dunia dapat dijadikan sebagai media, seperti : guru, teman sebaya, buku teks, lingkungan sekolah dan luar sekolah.

(dalam

http://gusdanela.blogspot.com/2014/

02/pengertian-media-menurut-

beberapa ahli.html)

Pengertian pendidikan

karakter menurut Lickona (dalam http://belajarpsikologi.com/pengertia n-pendidikan-karakter/) pendidikan karakter adalah suatu usaha untuk membimbing seseorang mampu memahami serta melakukan pengamalan nilai - nilai karakter bangsa. Dengan demikian media pendidikan karakter merupakan suatu perantara yang dapat digunakan dalam menciptakan suatu pemahaman pada anak sehingga anakmemiliki nilai karakter yang diharapkan.

\section{Nilai - nilai yang terkandung dalam kisah Dhruva sebagai Media Pendidikan Karakter Pada Anak:}

1. Nilai Religius, yakni sikap yang mencerminkan patuh terhadap ajaran agama yang dianutnya serta toleransi dengan umat beragama lain. Nilai religius dalam kisah Dhruva tampak dari bagian yang menceritakan bahwa Dhruva bertapa kehadapan Dewa Vusnu dengan tulus dan kemudian Visnu menampakan wujudnya di hadapa Dhruva. Hal ini menunjukkan wujud bhakti seorang bhakta terhadap Tuhannya.

Dikutip dari nasihat Suniti kepada Druva bahwa manusia menderita atau bahagia itu bergantung pada perbuatan masa lampaunya, dari perkataan tersebut mengajarkan tentang adanya karma phala. Apapun yang kita peroleh saat ini merupakan hasil dari perbuatan yang telah kita lakukan. Oleh karena itu kita tidak boleh marah maupun kecewa dengan apa yang diperoleh saat ini, justru sebaliknya kita harus bersyukur atas apapun pemberian Tuhan dan berusaha menjadikan diri menjadi lebih baik dengan memahami agama, menjalankan ajarannya dan menjauhi larangannya. Dipahami lebih lanjut dalam kitab Sarasamusccaya sebagai berikut:

Matangnyan haywa juga wwang manastapa, an tan paribhawa, si dadi wwang ta pwa kagongakena ri ambek apayapan paramadulabha iking 
ADI WIDYA: Jurnal Pendidikan Dasar

si janmamanusa ngaran ya, yadyapi candalayoni tuwi (Sarasamuccaya 3)

Terjemahannya:

Oleh karena itu, janganlah sekali - kali bersedih hati; sekalipun hidupmu tidak makmur; dilahirkan menjadi manusia itu, hendaklah menjadikan kamu berbesar hati, sebab amat sukar untuk dapat dilahirkan menjadi manusia, meskipun kelahiran hina sekalipun.

2. Nilai mandiri dan percaya diri, yakni sikap dan prilaku tidak bergantung dengan orang lain dan selalu berusaha sendiri dengan rasa ercaya diri yang dimiliki dalam mengerjakan tugas - tugas. Nilai mandiri dan percaya diri dalam kisah Dhruva dapat dilihat dari perkataan Dhruva "aku akan menunjukkan padamu apa yang bisa aku lakukan. Biarkan Uttama yang mendapatkan tahta, karena aku tidak mau memiliki sesuatu yang menjadi milik orang lain. Dengan usahaku sendiri" dari perkataan tersebut mengajarkan bahwa percayalah pada diri sendiri dan jangan selalu mengandalkan orang lain dan cobalah untuk percaya pada diri sendiri, bukan tidak mugkin sesuatu yang dilakukan sendiri bisa lebih baik daripada selalu bergantung pada orang lain. Karena sekecil apapun hasil yang kita dapatkan akan jauh lebih bermakna apabila dilakukan dengan usaha sendiri.

3. Nilai menghargai prestasi, yakni sikap dan tindakan dalam berteman maupun bermasyarakat dengan memiliki rasa kebersamaan dan mengakui, serta menghormati keberhasilan orang lain. nilai menghargai prestasi dalam kisah Dhruva terlihat dari sikap Dhruva yang tidak memiliki rasa iri pada Uttama. Sekalipun Uttama mampu mendapatkan kasih sayang ayahnya secara penuh, Dhruva ikhlas menerimanya. Dengan demikian dapat mengajarkan kita untuk selalu menerima kekalahan dan prestasi yang di dapatkan oleh teman. Janganlah saling membeci, dan menaruh rasa iri pada setiap pencapaian yang di dapat orang lain, sebaliknya jadikanlah hal itu sebagai motivasi dalam meraih hal yang dicita - citakan.

4. Nilai Toleransi, yakni sikap menghargai dan menerima perbedaan dalam bidang apapun. Baik agama, ras, suku, etnis, pendapat, dan lain sebagainya. Nilai toleransi tercermin dari sikap Suniti yang menghargai prilaku suaminya yang kurang adil terhadap dirinya dan anaknya. Dia menyadari bahwa Uttanapada tidak hanya memilikinya namun jua memiliki Suruchi dan Uttama sehingga Suniti tidak pernah mempermasalahkan hal tersebut. Hal itu mengajarkan kita untuk selalu dapat menghargai dan menerima hak dan kewajiban orang lain yang berbeda dengan kita. Karena ketika toleransi dan rasa saling memiliki itu ada, maka mendapat suatu kedamaianbukanlah suatu hal yang sulit.

5. Nilai komunikatif, yakni sikap dan tindakan mampu mendorong dirinya untuk mau berkomunikasi dengan orang lain untuk 
ADI WIDYA: Jurnal Pendidikan Dasar

: http://ejournal.ihdn.ac.id/index.php/AW

menghasilkan sesuatu yang berguna bagi dirinya dan masyarakat. Dalam kisah Dhruva dilihat bahwa Dhruva menceritakan tentang apa yang telah terjadi padanya sehingga ia mendapatkan nasihat oleh ibu dan juga ketujuh maha Rsi. Hal ini mengajarkan bahwa segala sesuatu haru di komunikasikan. Baik kepada teman maupun orang tua, karena ketika kita sudah berani mengkomunikasikannya maka akan ada jalan untuk mengatasi permasalahan yang dihadapi.

\section{SIMPULAN}

Dalam mempelajari agama, tidaklah sulit karena kini ajaran agama sudah tertuang dalam bentuk cerita yang disusun dalam Itihasa dan Puraana. Itihasa dan Puraana merupakan kesusastraan hindu yang masih relevan hingga saat ini dan di terima berbagai kalangan masyarakat. Jika disadari banyak nilai yang terkandung di dalamnya, tidak hanya menyangkut ajaran agama namun juga menandung nilai - nilai pendidikan seperti nilai etika dan moralitas. Membangun generasi muda yang berkarakter tidaklah mudah namun bukan berarti mustahil untuk diwujudkan. Melalui karakter tokoh yang di tonjolkan dalam puraana dapat dijadikan sebagai media penanaman pendidikan karakter pada anak, yang diharapkan dapat berkontribusi dalam pendidikan anak berkarakter baik pendidikan informal dalam keluarga maupun pendidikan formal di sekolah.

\section{DAFTAR PUSTAKA}

Debroy Bibek, dan Dipavali Debroy. 2000.

PURANA.Surabaya:Paaramita

Maswinara, I Wayan.2001.Visnu Purana.Surabaya:Paaramita

Kajeng, I Nyoman, dkk. 1997.Sarasamuccaya.Surabaya : Paaramita.

Abd. Rahman Shaleh.2005. Pendidikan Agama dan Pengembangembangan untuk Bangsa.Jakarta: PT. Raja Grafindo Persada

Wiguna, I. M. A. (2018). Karakter Anak Suputra dalam Itihasa dan Purana (Sebuah Kontemplasi).

Wiguna, I. M. A. (2018, January). Mengurai Nilai-Nilai Moral Dalam Satua Sebagai Media Pendidikan Karakter Di Era Global. Prosiding Seminar Nasional Kearifan Lokal Indonesia Untuk Pembangunan Karakter Universal 2015 (pp. 232-241).

Yupardhi,

Sayang.2012.Pembentukan

Karakter Bangsa Melalui Pendidikan dan Pengabdian Bernuansa

Spiritual.Surabaya:Paaramita

http://belajarpsikologi.com/pengertia n-pendidikan-karakter/

http://rumahinspirasi.com/18-nilaidalam-pendidikan-karakterbangsal

http://gusdanela.blogspot.com/2014/ 02/pengertian-media-menurutbeberapa ahli.html 